\title{
Towards the validation of high-throughput sequencing (HTS) for routine plant virus diagnostics: measurement of variation linked to HTS detection of citrus viruses and viroids
}

Rachelle Bester ${ }^{1}$, Glynnis Cook², Johannes H. J. Breytenbach², Chanel Steyn ${ }^{2,3}$, Rochelle De Bruyn ${ }^{1,2}$ and Hans J. Maree ${ }^{1,4^{*}}$ (D)

\begin{abstract}
Background: High-throughput sequencing (HTS) has been applied successfully for virus and viroid discovery in many agricultural crops leading to the current drive to apply this technology in routine pathogen detection. The validation of HTS-based pathogen detection is therefore paramount.

Methods: Plant infections were established by graft inoculating a suite of viruses and viroids from established sources for further study. Four plants (one healthy plant and three infected) were sampled in triplicate and total RNA was extracted using two different methods (CTAB extraction protocol and the Zymo Research Quick-RNA Plant Miniprep Kit) and sent for Illumina HTS. One replicate sample of each plant for each RNA extraction method was also sent for HTS on an Ion Torrent platform. The data were evaluated for biological and technical variation focussing on RNA extraction method, platform used and bioinformatic analysis.
\end{abstract}

Results: The study evaluated the influence of different HTS protocols on the sensitivity, specificity and repeatability of HTS as a detection tool. Both extraction methods and sequencing platforms resulted in significant differences between the data sets. Using a de novo assembly approach, complemented with read mapping, the Illumina data allowed a greater proportion of the expected pathogen scaffolds to be inferred, and an accurate virome profile was constructed. The complete virome profile was also constructed using the lon Torrent data but analyses showed that more sequencing depth is required to be comparative to the Illumina protocol and produce consistent results. The CTAB extraction protocol lowered the proportion of viroid sequences recovered with HTS, and the Zymo Research kit resulted in more variation in the read counts obtained per pathogen sequence. The expression profiles of reference genes were also investigated to assess the suitability of these genes as internal controls to allow for the comparison between samples across different protocols.

Conclusions: This study highlights the need to measure the level of variation that can arise from the different variables of an HTS protocol, from sample preparation to data analysis. HTS is more comprehensive than any assay previously used, but with the necessary validations and standard operating procedures, the implementation of HTS as part of routine pathogen screening practices is possible.

*Correspondence: hjmaree@sun.ac.za

${ }^{1}$ Department of Genetics, Stellenbosch University, Private Bag X1, Matieland 7602, South Africa

Full list of author information is available at the end of the article permits use, sharing, adaptation, distribution and reproduction in any medium or format, as long as you give appropriate credit to the original author(s) and the source, provide a link to the Creative Commons licence, and indicate if changes were made. The images or other third party material in this article are included in the article's Creative Commons licence, unless indicated otherwise in a credit line to the material. If material is not included in the article's Creative Commons licence and your intended use is not permitted by statutory regulation or exceeds the permitted use, you will need to obtain permission directly from the copyright holder. To view a copy of this licence, visit http://creativecommons.org/licenses/by/4.0/. The Creative Commons Public Domain Dedication waiver (http://creativeco mmons.org/publicdomain/zero/1.0/) applies to the data made available in this article, unless otherwise stated in a credit line to the data. 
Keywords: CTV, Citrus tristeza virus, Next-generation sequencing, Bioinformatics

\section{Background}

The prevention and management of plant diseases largely depend on accurate identification of pathogens. Rapid and specific detection assays are required that need continuous development and optimisation as technology and knowledge of the pathogens advance. The increased use of high-throughput sequencing (HTS) for the construction of virome profiles of many agricultural crops has led to the discovery of many new viruses [1-13]. Some viruses cause, or are associated with, economically damaging diseases necessitating detection tools that can reliably detect them in the shortest timeframe. The successful control of viruses and viroids in commercial crops are directedly correlated to the effectiveness of the detection assays used to screen plant propagation material. The challenges and opportunities of HTS for virus and viroid detection has been highlighted previously [14-17] and in the United States of America, HTS already forms part of their clean plant propagation programs by creating a provisional release category based on a HTS-negative selection [16]. This category of plants is then allowed to be propagated in designated approved areas pending the completion of all conventional laboratory tests. This allows accelerated multiplication of plant material prior to official clean status certification and release.

The generation of sequence data using various metagenomic and enrichment strategies and the development of the associated bioinformatic pipelines has led to the identification of many known and novel viral sequences [18]. The confirmation of these agents is usually subsequently verified using a PCR or RT-PCR assay designed using the HTS data generated in the first place. The question is therefore whether HTS can be used as a reliable standalone detection tool if the necessary parameters i.e. sensitivity and reliability can be validated as for any other detection assay. As the use of HTS is more routinely employed, the need to establish the influence of variables such as sample preparation, sequencing platforms and data analysis on the output becomes imperative. If HTS can be validated for sensitivity and specificity within a specific pathosystem, it can be used as a standalone detection assay to provide a fast and reliable diagnostic for any viral disease. For known viruses, a HTS detection assay has great application value for broad based detection of viruses in high value plant material at the post import quarantine stage or in the clean-status verification of nuclear or mother plant material of plant improvement schemes. One limitation to this assay would be the comprehensiveness of the reference database used.

The current consensus is that HTS data analyses and the interpretation of the results for plant viral diseases require expertise in both bioinformatics and plant virology [14, 15]. Nevertheless, numerous studies report attempts to streamline the analysis and to find a one size fits all solution to the bioinformatic component of the HTS assay to inform a diagnostic call [19-36]. There are also different options for target nucleic acids to be sequenced, most popular being total RNA (commonly ribo-depleted), small RNA (sRNA) and double stranded RNA depending on the application of the HTS assay. A popular strategy employed for the detection of plant viruses is sRNA sequencing. This strategy can effectively detect viruses with DNA or RNA genomes. However, sRNAs are generated as a host defence response to virus infection and a weaker response will result in lower levels of sRNAs that could impact negatively on this approach's ability to detect these specific viruses [37, 38]. The effect of different bioinformatic pipelines was also evaluated previously in a large-scale performance test on sRNA data and the variation in results were significant [39]. The advantages of ribo-depleted RNA sequencing over sRNA sequencing for virus detection were also highlighted previously $[37,40]$.

Even though plant virologists without training in bioinformatics can benefit from automated pipelines with graphical user interfaces, the quality and accuracy of the output is reliant on the quality of the input. The input to an HTS assay incorporates the whole process from sample collection, wet laboratory processing and data generation including data quality control. All the quality control measures up to data QC are the same or similar to any other sensitive molecular assay and need to be incorporated as assay variables. To ensure optimum data analysis, data should be evaluated for the different quality parameters, including not only the quality scores of each base, but also the sequencing depth. All these parameters can impact on the specificity, sensitivity and repeatability of the diagnostic result. The specific application of HTS will determine the acceptable level of variation that is tolerable. Identifying the exact virus or viroid variant, for example, is not required for pathogen detection. Applications of HTS are therefore varied and include both detection and discovery. It is important to identify the application and to tailor the assay, data analysis and interpretation accordingly. 
(See figure on next page.)

Fig. 1 Visual representation of experimental layout. The establishment of plant material and the selection of samples subjected to high-throughput sequencing (HTS) is illustrated. Source plant A is infected with citrus tristeza virus (CTV) (genotypes RB, T3, T30, VT and S1), citrus virus A (CiVA), hop stunt viroid (HSVd), citrus dwarfing viroid (CDVd) and citrus exocortis viroid (CEVd), source plant B with only 'Candidatus Liberibacter africanus' (CLaf)) and source plant C with citrus tatter leaf virus (CTLV)

The citrus industry is one of the largest fruit industries worldwide with South Africa being the second largest fresh citrus exporter [41]. However, citrus pathogens can lead to a reduction in yield and threaten cultivar sustainability. One of the most devastating and complex viral pathogens of citrus species locally and worldwide is the closterovirus, citrus tristeza virus (CTV) [42, 43]. Other pathogens sporadically detected in non-certified citrus in South Africa include citrus tatter leaf virus (CTLV) and viroids such as hop stunt viroid (HSVd), citrus dwarfing viroid (CDVd) and citrus exocortis viroid (CEVd). More recently citrus virus $\mathrm{A}$ (CiVA) was detected in older orchards [44].

Viruses and viroids that are mainly spread through vegetative propagation can be effectively controlled through the use of certification programmes to generate virus free budwood/cuttings for propagation. HTS can detect multiple pathogens within a single assay, and has the advantage that data can be re-evaluated as new viral agents and variants are added to global databases.

In this study, Citrus sinensis plant material infected with a range of viruses, including positive and negative sense RNA viruses, and viroids were established and subjected to HTS to evaluate the level of biological and technical variation that can arise from the RNA extraction method, sequencing platform and bioinformatic pipeline used. This study evaluated HTS variation for a citrus virome in order to use HTS as a standalone detection assay.

\section{Methods}

\section{Plant material}

A set of plants (C. sinensis cv. 'Madam Vinous', sweet orange) were established from seed and each graft inoculated in February 2019 with three source plants infected with a pre-determined range of pathogens (citrus tristeza virus (CTV), citrus virus A (CiVA), citrus tatter leaf virus (CTLV), hop stunt viroid (HSVd), citrus dwarfing viroid (CDVd) and citrus exocortis viroid (CEVd)). Source plant A was infected with CTV genotypes RB, VT, T3, T30, S1 and A18, CiVA, HSVd, CDVd and CEVd, source plant $B$ with 'Candidatus Liberibacter africanus' (CLaf) and source plant C only contained CTLV. These source plants are well characterised sources maintained at Citrus Research International (CRI) in Nelspruit, South Africa. Plants were maintained in a temperature-controlled greenhouse $\left(24-28^{\circ} \mathrm{C}\right)$ with natural light in summer, but with additional lighting provided in winter months to supply a total of $16 \mathrm{~h}$ light per day. The infection status of the graft inoculated plants were confirmed with RTPCR eight months post inoculation. Briefly, total RNA was extracted from leaves using an acid phenol extraction buffer [45]. Complementary DNA (cDNA) was synthesized from $1 \mu \mathrm{g}$ of total RNA using $0.1 \mu \mathrm{g}$ of random hexamers (Inqaba Biotec), dNTPs (1 mM final concentration) (Thermo Scientific), $100 \mathrm{U}$ of RevertAid H Minus Reverse Transcriptase (Thermo Scientific) and $10 \mathrm{U}$ of RiboLock RNase Inhibitor (Thermo Scientific) in a final volume of $20 \mu \mathrm{l}$ according to manufacturer's instructions. A $1 \mu \mathrm{l}$ aliquot of cDNA was added to $9 \mu \mathrm{l}$ of PCR reaction mixture containing $1 \times \mathrm{GoTaq}^{\circledR}$ G2 Hot Start Master Mix (Promega) and $0.375 \mu \mathrm{M}$ forward and reverse primers (IDT) (Additional file 1). Cycle conditions for the different assays included an initial denaturation step at $94{ }^{\circ} \mathrm{C}$ for $2 \mathrm{~min}$, followed by 35 cycles of $94{ }^{\circ} \mathrm{C}$ for $20 \mathrm{~s}$, primer specific annealing temperature (Additional file 1) for $60 \mathrm{~s}$, elongation at $72{ }^{\circ} \mathrm{C}$ for $20 \mathrm{~s}$ and a final extension of $72{ }^{\circ} \mathrm{C}$ for $5 \mathrm{~min}$. One healthy plant and three plants infected with a pathogen complement including HSVd, CDVd, CEVd, CTV, CiVA and CTLV were selected for further analysis (Fig. 1).

\section{Total RNA extractions for HTS}

A representative leaf sample was taken from each of the four experimental plants, and from this sample three random samples were taken for further processing. Total RNA was extracted from these three samples per plant using two different extraction methods (Fig. 1). One gram of leaf midribs of each sample were homogenised in a Bioreba extraction bag and total RNA extracted using a modified CTAB extraction protocol [46]. An Ornithogalum thyrsoides leaf sample infected with Ornithogalum mosaic virus (OrMV) was also subjected to the CTAB extraction protocol as a nontarget positive control. The Quick-RNA Plant Miniprep Kit (Zymo Research) was used to extract total RNA from $0.2 \mu \mathrm{g}$ of leaf midribs from each sample homogenised in liquid nitrogen. The three samples from each of the four plants were sequenced on the Illumina HTS platform and one sample of each plant was sequenced on the Ion Torrent HTS platform. For the samples sequenced on both platforms, the same RNA extract was divided and shipped to the 


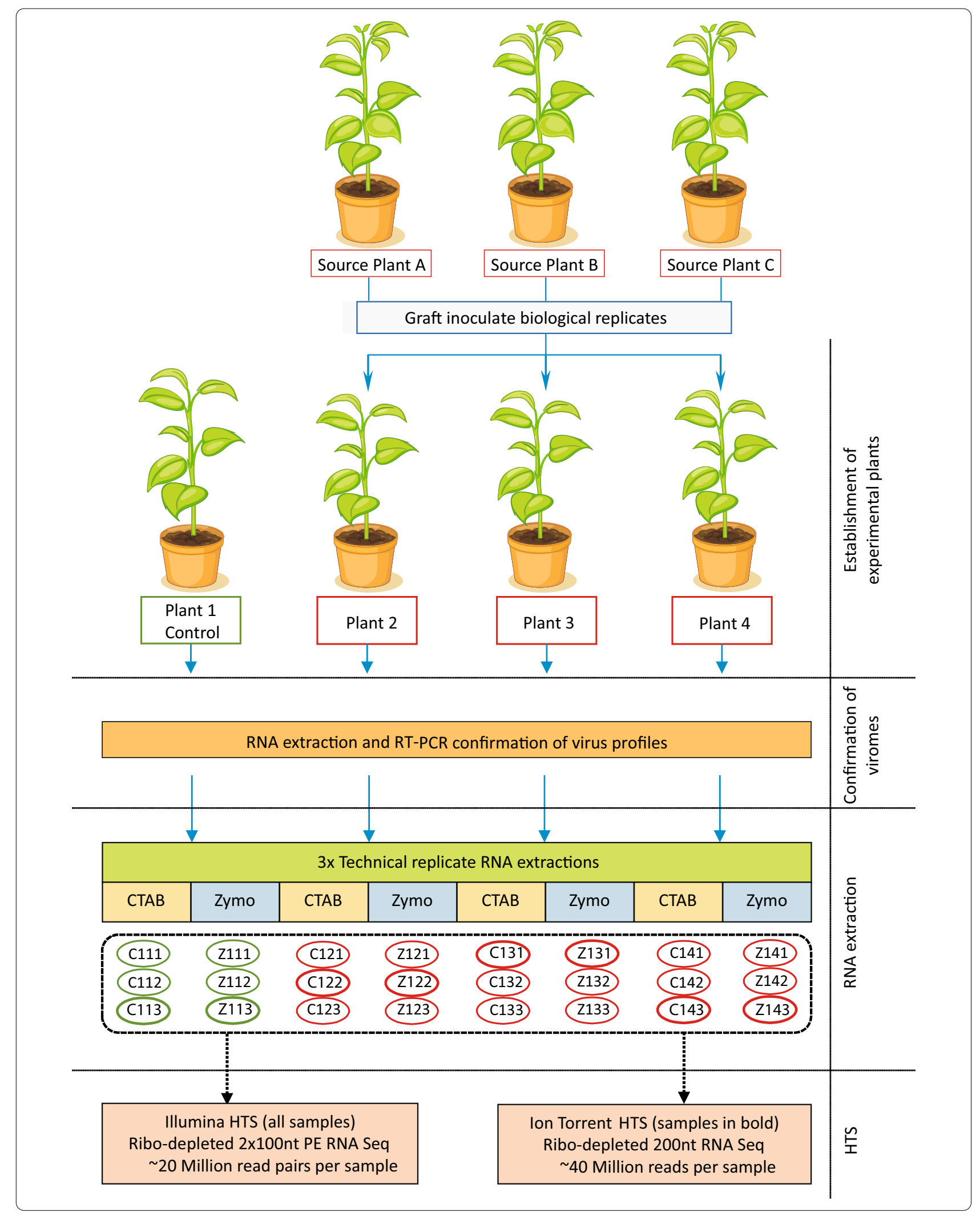


respective service providers. The quality of the RNA was assessed independently at each service provider using the Agilent 2100 BioAnalyzer to determine the RNA integrity number (RIN).

\section{CTV RT-PCR genotyping}

Two-step RT-PCRs were performed to determine the CTV genotype status of the graft inoculated plants. Complementary DNA (cDNA) was synthesized from $1 \mu \mathrm{g}$ of total RNA using $0.15 \mu \mathrm{g}$ of random hexamers (Promega) and Maxima reverse transcriptase (Thermo Scientific) in a final volume of $20 \mu \mathrm{l}$ according to manufacturer's instructions. A 2- $\mu$ l aliquot of cDNA was added to $25 \mu$ of PCR reaction mixture containing $1 \times$ KAPA Taq buffer A (Roche), $0.2 \mathrm{mM}$ dNTP mix (Thermo Scientific), $0.4 \mu \mathrm{M}$ forward and reverse primers (IDT) (Additional file 1), and 1.25 U/ $\mu \mathrm{l} \mathrm{KAPA} \mathrm{Taq} \mathrm{DNA} \mathrm{poly-}$ merase (Roche). Cycle conditions for the different assays included an initial denaturation step at $94{ }^{\circ} \mathrm{C}$ for $5 \mathrm{~min}$, followed by 35 cycles of $94{ }^{\circ} \mathrm{C}$ for $30 \mathrm{~s}$, primer specific annealing temperature (Additional file 1) for $30 \mathrm{~s}$, and elongation at $72{ }^{\circ} \mathrm{C}$ for $30 \mathrm{~s}$ and a final extension of $72{ }^{\circ} \mathrm{C}$ for $7 \mathrm{~min}$.

\section{High-throughput sequencing}

Twenty-four ribo-depleted RNA libraries, representing three technical replicates of RNA extracted from four $C$. sinensis plants with two total RNA extraction methods, were constructed with the Illumina TruSeq Stranded Total RNA Sample Preparation kit with Plant Ribo-Zero at Macrogen (South Korea) (Fig. 1). Paired-end HTS $(2 \times 100 \mathrm{bp})$ was performed on an Illumina NovaSeq 6000 instrument (Macrogen, South Korea). The nontarget positive control RNA originating from Ornithogalum was also subjected to the Illumina sequencing protocol.

Eight RNA samples, representing one technical replicate of each of the four $C$. sinensis plants extracted with two RNA extraction methods, were ribo-depleted (RiboMinus ${ }^{\mathrm{TM}}$ Plant Kit for RNA-Seq, ThermoFisher Scientific), and sequencing libraries were constructed (Ion Total RNA-Seq Kit v2.0, ThermoFisher Scientific) (Central Analytical Facility (CAF), Stellenbosch University) (Fig. 1). Single-end (200 bp chemistry) high-throughput sequencing was performed on an Ion Torrent ${ }^{\mathrm{TM}}$ Proton $^{\mathrm{TM}}$ instrument (CAF, Stellenbosch University).

The service providers were requested to provide 20 million read pairs per sample from Illumina sequencing and 40 million single end reads from Ion Torrent.

\section{Quality assessment of HTS data}

Adapter sequences were removed from the Illumina data and data was trimmed for quality using Trimmomatic [47] (SLIDINGWINDOW of 3 nts with Q20, MINLEN of 20 nts). The Ion Torrent data was processed by CAF using the default pipeline of the Torrent Suite software V5.12.0 (Thermo Fisher) including the removal of polyclonal reads and low quality reads, $3^{\prime}$ trimming using a 30 nt moving window and a quality score of 15, 6 nt adapter match trimming and a removal of reads shorter than 8 nts.

\section{De novo assemblies}

Both the trimmed Illumina and Ion Torrent data were subjected to de novo assemblies using SPAdes 3.14 [48] and CLC genomics Workbench 11.0.1 (CGW) (Qiagen) (default parameters). SPAdes de novo assembled scaffolds were identified using BLAST + standalone against a local copy of the NCBI GenBank nucleotide database using the Blastn algorithm. The scaffolds with no Blastn hits were mapped to the $C$. sinensis host genome (C.sinensis Hzau_v2.0_genome) [49] and the unmapped scaffolds (classified as "Number of scaffolds not mapped" in Additional file 2) were subjected to Blastx against a local copy of the NCBI GenBank non-redundant database.

To perform the CGW assembly both the Illumina and Ion Torrent data were imported using the appropriate tool for Illumina or Ion Torrent fastq files, respectively. Subsequently the data was de novo assembled (default parameters) and the resulting contigs were identified using Blastn.

\section{Read mapping}

All the quality trimmed reads were mapped to reference genomes extracted from Genbank. These references included the expected viruses and viroids (CiVA, MT720885, MT720886; CTLV, MH108976; CTV isolate B390-5, KU883265; CDVd, KY110718; CEVd, KY110721; HSVd, KY110716) as well as nontarget variants of expected viruses (CTV isolate GFMS12-8, MK033511; HSVd, KY110717), and the nontarget positive control virus (OrMV, KY769694.1). The Burrows-Wheeler Alignment Tool (BWA) version 0.7.13 [50] were utilised and the mapped reads filtered for $95 \%$ similarity for a $90 \%$ read fraction using samtools version 1.10 [51]. The genome coverage (span from the first to the last base of the genome) for each reference genome was calculated using samtools.

The CTV genotype status of each plant sample was also confirmed with read mapping using the pipeline and criteria established previously [52].

Additionally, 12 genes previously evaluated as C. sinensis reference genes were identified from literature [53] and retrieved from GenBank using the best Blastn hit (online NCBI tool) of the Arabidopsis Thaliana orthologs against the organism C. sinensis (Table 1). All the quality trimmed reads were mapped to the 
Table 1 Gene and pathogen accessions used as reference sequences for read mapping

\begin{tabular}{|c|c|c|c|c|c|}
\hline \multicolumn{3}{|l|}{ Accession } & \multicolumn{2}{|l|}{ Name } & \multirow[t]{2}{*}{ Length } \\
\hline $\begin{array}{l}\text { Arabidopsis thaliana } \\
\text { Gene locus identi- } \\
\text { fier }\end{array}$ & Citrus sinensis accession & Gene symbol & Arabidopsis thaliana gene name & Citrus sinensis gene name & \\
\hline At2g28390 & XM_006488024.3 & SAND & SAND family protein & $\begin{array}{l}\text { Vacuolar fusion protein MON1 } \\
\text { homolog (LOC102625488) }\end{array}$ & 2415 \\
\hline At5g08290 & XM_006484464.3 & DIM1 & DIM1 homolog/YLS8 & $\begin{array}{l}\text { Thioredoxin-like protein YLS8 } \\
\text { (LOC102629695) }\end{array}$ & 727 \\
\hline At2g32170 & XM_006481276.3 & N/A & Unknown protein & $\begin{array}{l}\text { Carnosine N-methyltransferase- } \\
\text { like (LOC102617870) }\end{array}$ & 1773 \\
\hline At5g15710 & XM_006482390.2 & FBOX & F-box family protein & $\begin{array}{l}\text { F-box/kelch-repeat protein } \\
\text { At5g15710 (LOC102621205) }\end{array}$ & 4479 \\
\hline At3g53090 & XM_025099888.1 & UPL7 & Ubiquitin-protein ligase 7 & $\begin{array}{l}\text { E3 ubiquitin-protein ligase UPL7 } \\
\text { (LOC102621690) }\end{array}$ & 3888 \\
\hline At5g25760 & XM_006476013.2 & UBC21 & Ubiquitin-conjugating enzyme 21 & $\begin{array}{l}\text { Protein PEROXIN-4 } \\
\quad(\text { LOC102618324) }\end{array}$ & 1029 \\
\hline At3g01150 & XM_025099846.1 & PTB1 & $\begin{array}{l}\text { Polypyrimidine tract-binding } \\
\text { protein } 1\end{array}$ & $\begin{array}{l}\text { Polypyrimidine tract-bind- } \\
\text { ing protein homolog } 1 \\
\text { (LOC102618721) }\end{array}$ & 1708 \\
\hline At1g13440 & XM_006476919.3 & GAPC2 & $\begin{array}{l}\text { Glyceraldehyde-3-phosphate } \\
\text { dehydrogenase C2 }\end{array}$ & $\begin{array}{l}\text { Glyceraldehyde-3-phosphate } \\
\text { dehydrogenase GAPC1, cyto- } \\
\text { solic (LOC102624117) }\end{array}$ & 1464 \\
\hline At4g27960 & XM_006490521.3 & UBC9 & Ubiquitin conjugating enzyme 9 & $\begin{array}{l}\text { Ubiquitin-conjugating enzyme } \\
\text { E2 } 10 \text { (LOC102614401) }\end{array}$ & 961 \\
\hline At3g18780 & XM_006464503.3 & $\mathrm{ACT} 2$ & Actin-2 & Actin-7 (LOC102577980) & 1786 \\
\hline At5g60390 & XM_006485840.3 & EF-1a & Elongation factor 1-alpha & $\begin{array}{l}\text { Elongation factor 1-alpha } \\
\quad(\text { LOC102613486) }\end{array}$ & 1870 \\
\hline At1G20010 & XM_006473602.3 & TUB & Beta-Tubulin & $\begin{array}{l}\text { Tubulin beta-6 chain } \\
\text { (LOC102631140) }\end{array}$ & 1756 \\
\hline Genbank accession & & Pathogen abbreviation & Pathogen name & & \\
\hline KU883265 & & CTV & Citrus tristeza virus B390-5 RB & & 19,270 \\
\hline MK033511 & & CTV & Citrus tristeza virus GFMS12-8 T68 & & 19,246 \\
\hline МH108976.1 & & CTLV & $\begin{array}{l}\text { Citrus tatter leaf virus isolate } \\
\text { TL101 }\end{array}$ & & 6494 \\
\hline MT720885 & & CiVA & Citrus virus A RNA1 isolate 1.8 & & 6690 \\
\hline MT720886 & & CiVA & Citrus virus A RNA2 isolate 1.8 & & 2731 \\
\hline KY110716.1 & & HSVd & Hop stunt viroid strain R140902-7 & & 302 \\
\hline KY110717.1 & & HSVd & $\begin{array}{l}\text { Hop stunt viroid strain R120621-2 } \\
\text { (Cachexia) }\end{array}$ & & 295 \\
\hline KY110718.1 & & CDVd & $\begin{array}{l}\text { Citrus dwarfing viroid strain } \\
\text { R140910-12 }\end{array}$ & & 297 \\
\hline KY110721.1 & & CEVd & $\begin{array}{l}\text { Citrus exocortis viroid strain } \\
\text { R140902-18 }\end{array}$ & & 372 \\
\hline
\end{tabular}

reference genes using BWA and the gene coverage (span from the first to the last base of the genome) for each reference gene was calculated using samtools.

The average distance between the paired-end Illumina reads was calculated by mapping the paired-end data to the C. sinensis chloroplast genome (DQ864733) using CGW (default parameters).

\section{Read count normalisation}

The read count of each reference gene, virus and viroid sequence was normalised for comparisons by calculating the transcripts per million (TPM) count. Firstly, the read count per kilobase of sequence (RPK) was calculated for each gene, virus and viroid sequence. After which the sum of all the RPKs were divided by a million to calculate the denominator for the transcripts per million (TPM) count for reference genes and pathogens separately. Each sequence's RPK was divided by the reference genes or 
pathogens specific denominator to normalise the read count for biological and technical variation between samples. The TPM count for each reference sequence was used to compare the proportion of reads that mapped to a specific reference in each sample. Statistical analyses were performed using $\mathrm{R}$ available from the Comprehensive R Archive Network (CRAN) [54]. The Kruskal-Wallis rank sum test was used to compare data distributions [55]. Principal component analysis were visualised using package ggbiplot [56].

\section{Sequencing depth simulation}

To assess the influence of data set size on the detection of virus and viroids using read mapping, data for each sample were sub-sampled randomly 10 times for 9 different subset sizes $(1000,5000,10,000,50,000,100,000$, $500,000,1,000,000,5,000,000,10,000,000$ reads) using seqtk (https://github.com/lh3/seqtk). The Illumina subsets were created in paired-end mode to have a total read count for each subset equal to the selected subset sizes (e.g. the 1000 reads subset from Illumina data contain 500 read pairs). The data subsets were mapped to the different reference genes or pathogen sequences using the abovementioned pipeline.

\section{Results}

\section{Plant material}

The plant material selected for HTS analysis was screened with RT-PCR and PCR to determine the infection status of the plants. The transmission of CLaf was unsuccessful and none of the plants selected for further analyses had a detectable CLaf infection. The negative control plant tested negative for all the pathogens tested for and the three infected plants tested positive for HSVd, CDVd, CEVd, CTV, CiVA and CTLV. The RT-PCRs to determine the CTV genotype status of the individual biological replicates confirmed the presence of CTV genotypes RB, VT, T3, T30 and S1.

The average RIN value for the RNA extracted for the HTS analysis with the CTAB method was $8.1( \pm 0.1$ standard deviation) and the average ribosomal RNA (rRNA) ratio was 5.5 ( \pm 1.3 standard deviation). The average RIN value for the RNA extracted with the Zymo Research kit was $7.9( \pm 0.5$ standard deviation) and the average ribosomal RNA (rRNA) ratio was $1.9( \pm 0.3$ standard deviation. The Zymo Research kit extracted RNA was flagged by Macrogen due to an abnormal 5S peak.

\section{Data quality}

On average 26 million paired-end reads were received per sample from the Illumina HTS. The quality of the data was high and after stringent quality trimming 96\% of the data per sample was retained (Additional file 2). The average read length per sample was 99 nucleotides (nt) and the average read distance between the $5^{\prime}$ ends of the paired end reads was 196 bases. An average of 4.7 giga bases of Illumina data was obtained per sample. The Ion Torrent HTS yielded an average of 40 million reads per sample (Additional file 2) with an average read length of $137 \mathrm{nt}$. An average of 5.6 giga bases of Ion Torrent data was obtained per sample.

\section{De novo assembly}

The Illumina data were de novo assembled using SPAdes into an average of 72,000 (CTAB extractions) and 79,000 (Zymo Research kit extractions) scaffolds with an average N50 of 1800 and 1600 nt, respectively (Additional file 2). The Ion Torrent data assembled into an average of 60,000 (CTAB RNA) and 18,000 (Zymo Research kit) scaffolds with an average N50 of 1300 and $1400 \mathrm{nt}$, respectively (Additional file 2).

The nontarget positive control Ornithogalum data assembled into 182,778 scaffolds with an N50 of 1219 . No citrus pathogens were identified in either the Ornithogalum data or the $C$. sinensis negative control sample data (Additional file 2). Ornithogalum mosaic virus (OrMV) and ornithogalum virus 3 (OV3) scaffolds were identified in the Ornithogalum sample (Additional file 2). Conversely, no OrMV or OV3 scaffolds were detected in the any of the $C$. sinensis samples (Additional file 2).

On average $98.4 \%$ of the SPAdes assembled scaffolds from the $C$. sinensis samples were identified as host plant, bacterial or fungal sequences (Fig. 2). On average, 1.2\% of the scaffolds were identified as virus sequences and $0.07 \%$ as viroid scaffolds (Fig. 2) and $0.2 \%$ of the scaffolds could not be identified. More viroid scaffolds were identified per sample from the Illumina data generated from the Zymo Research kit extracted RNA (0.23\%) compared to the data from the CTAB extractions (0.01\%) (Fig. 2).

Blastn analyses of the Illumina data showed the complete viral and viroid profiles expected for all the biological replicates (Additional file 2). However, no scaffolds with identity to viroid species CDVd (sample C122) and HSVd (sample C133), were assembled in one of the three technical replicates for two different biological replicates (both CTAB extractions). The de novo assembly of the Ion Torrent data performed less optimally with none of the 6 infected technical replicates containing scaffolds for the full pathogen complement (Additional file 2). No 


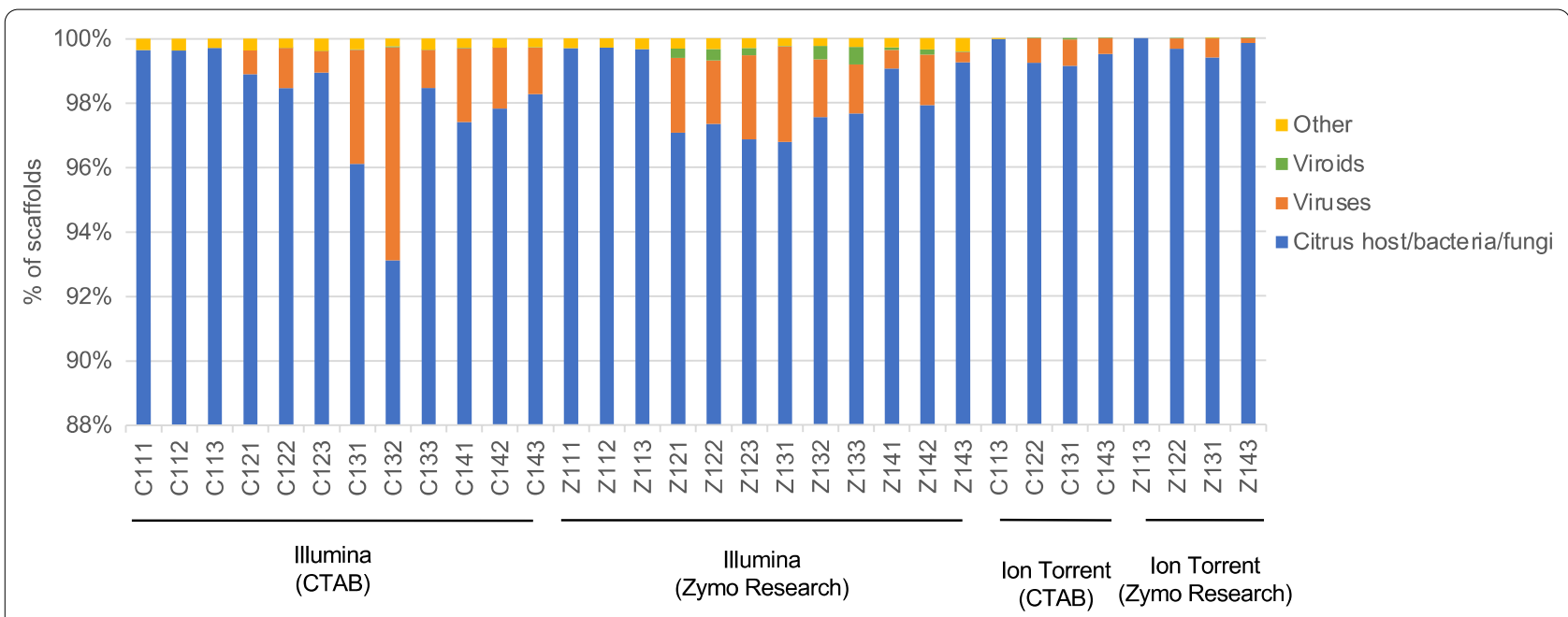

Fig. 2 Stacked column chart displaying the ratio of identified SPAdes scaffolds per sample. The percentage of scaffolds per sample identified using Blastn classified into four categories i.e. other (unidentified), viroids, viruses and Citrus sinensis host, bacteria and fungi is displayed

additional virus and viroid sequences were identified in any of the samples.

The Illumina data was assembled using CGW into an average of 66,315 contigs with an average N50 of 846 while the Ion Torrent data assembled into an average 12,347 contigs with an average N50 of 377 . Analyses of the Blastn results for the Illumina assembled contigs showed that only nine samples showed the complete viral and viroid profile. No contigs with identity to HSVd were assembled from the four CTAB extracted samples (representing two biological replicates) and five of the Zymo Research kit extracted samples (representing three biological samples). Contigs could not be assembled from the Ion Torrent data for CTLV in one CTAB extracted sample, HSVd in three samples (one CTAB and two Zymo Research kit extractions), CDVd in one CTAB extracted sample and CEVd in two samples (one per extraction method) (Additional file 2).

Viroid results were inconsistent irrespective of sequencing platform or de novo assembler used. Neither assembler yielded scaffolds/contigs for HSVd in sample C133 (Illumina), CTLV in sample Z122 (Ion Torrent), CEVd in sample Z131 (Ion Torrent) and HSVd and CEVd in sample Z143 (Ion Torrent).

\section{C. sinensis reference gene read mapping}

Reads were mapped to $12 C$. sinensis reference genes to identify biological variation and technical variation associated with RNA extraction method and sequencing platform (Table 1). For comparison of the proportion of reads that mapped to a gene in each sample the TPM values were used. A principal component analysis of the gene data showed clear data point clusters indicating the variation between the different RNA extraction and sequencing platform protocols (Fig. 3A).

The genes with the highest TPM count across all samples were GAPC2, EF-1a and ACT2 (Fig. 4). The genes with the lowest TPM count across all samples were FBOX and the unknown gene (Fig. 4). On average the highest coefficient of variance were observed with the CTAB extractions and the Illumina sequencing platform (Additional file 3). The ratio of each reference gene's TPM count shows a consistent pattern per sequencing platform (Fig. 4). The gene expression based on the relative TPM counts showed significant difference $(p$-value $<0.05)$ between platforms across and between extraction methods for 11 and 10 of the genes, respectively (Fig. 4, Additional file 4). The most variation in TPM count between platforms is observed for UPL7 which has a significant lower TPM count compared to the other genes in the Ion Torrent data for both extraction methods (p-value $<0.05$ ) (Additional file 4). GAPC2 also has a higher TPM count in the Ion Torrent data compared to the Illumina data (p-value <0.05) (Additional file 4). The relative ratio of EF-1a is higher in the Illumina data compared to the Ion Torrent data (p-value < 0.05) (Additional file 4).

The comparison between extraction methods showed no significant differences between the ratios of the gene TPM counts for the biological/technical replicates (Fig. 4). Only three of the genes showed significant differential expression between extraction methods independent of sequencing platform ( $\mathrm{p}$-value $<0.05$ ) (Additional file 4), while five genes showed significant differential expression between extraction methods for the Illumina sequencing platform and only three genes for the Ion Torrent sequencing platform ( $\mathrm{p}$-value $<0.05$ ) (Additional 

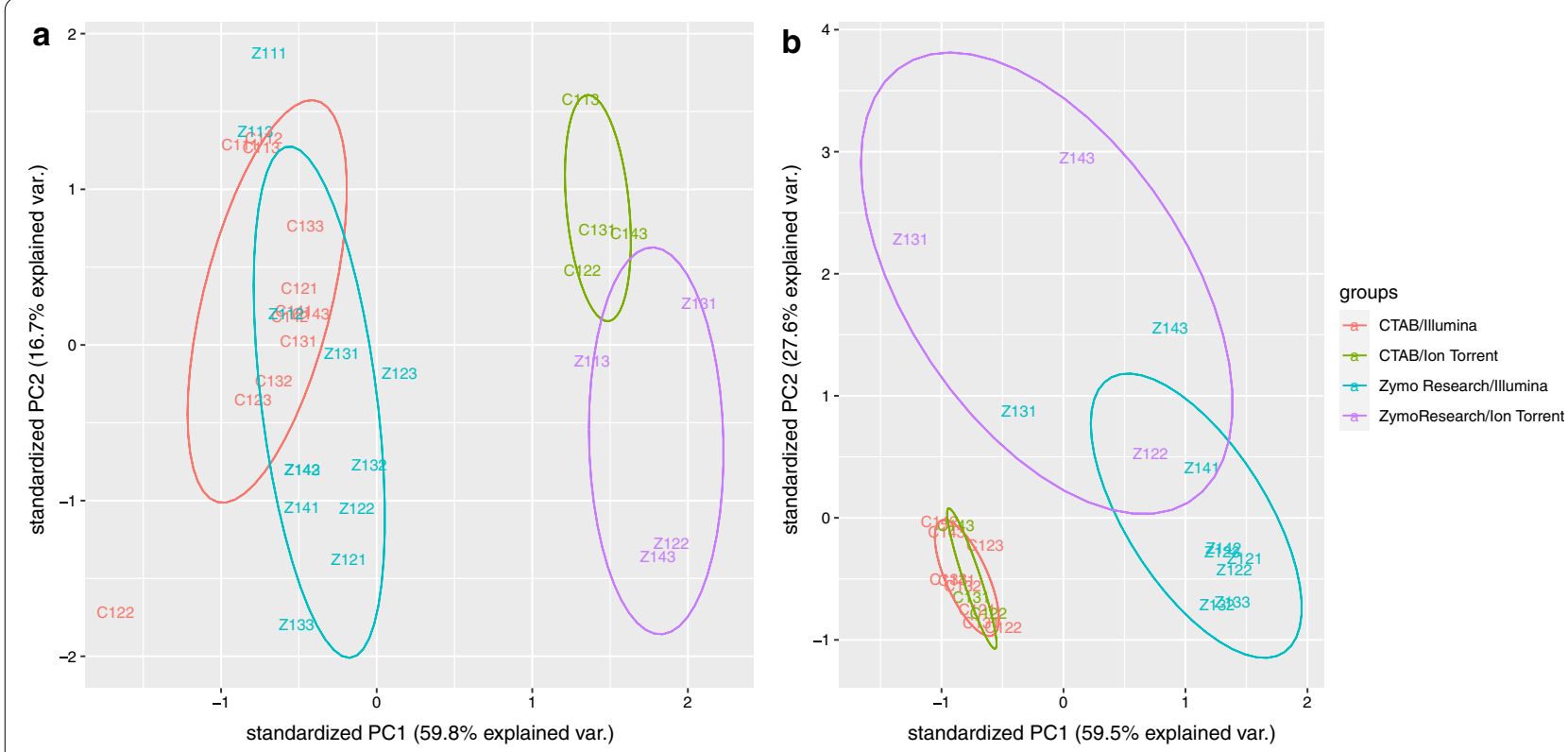

Fig. 3 Principal component analysis (PCA) plot of the transcript per million (TPM) counts. The trends exhibited by the expression profiles of the RNA extraction and sequencing platform protocols (CTAB/Illumina, Zymo Research/Illumina, CTAB/lon Torrent, Zymo Research/lon Torrent) are displayed for the reference gene TPM counts in $\mathbf{a}$ and for the pathogen TPM counts in $\mathbf{b}$. Samples are indicated with colours correlating to extraction method and sequencing platform and each colour circle represents a cluster of these designations

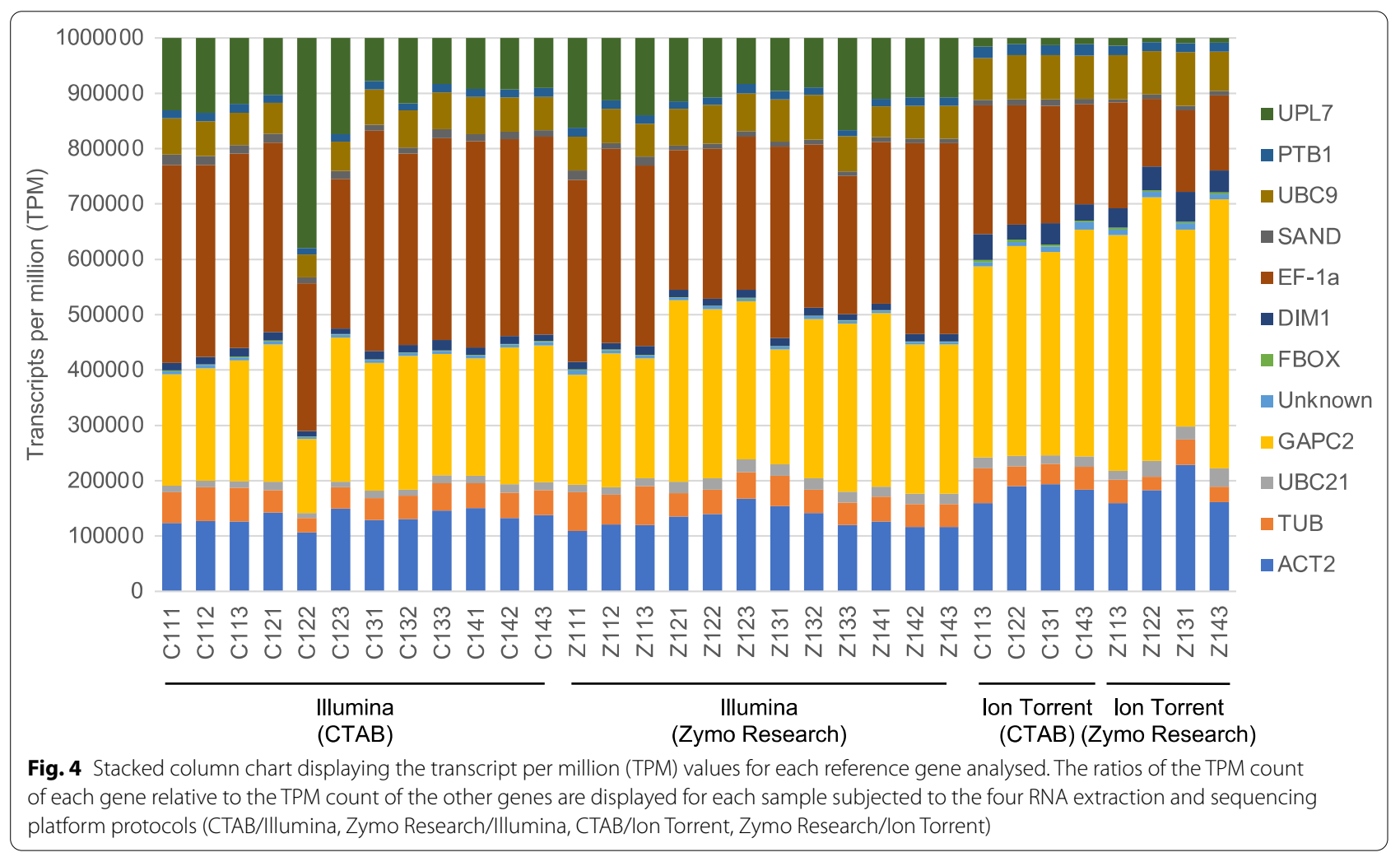




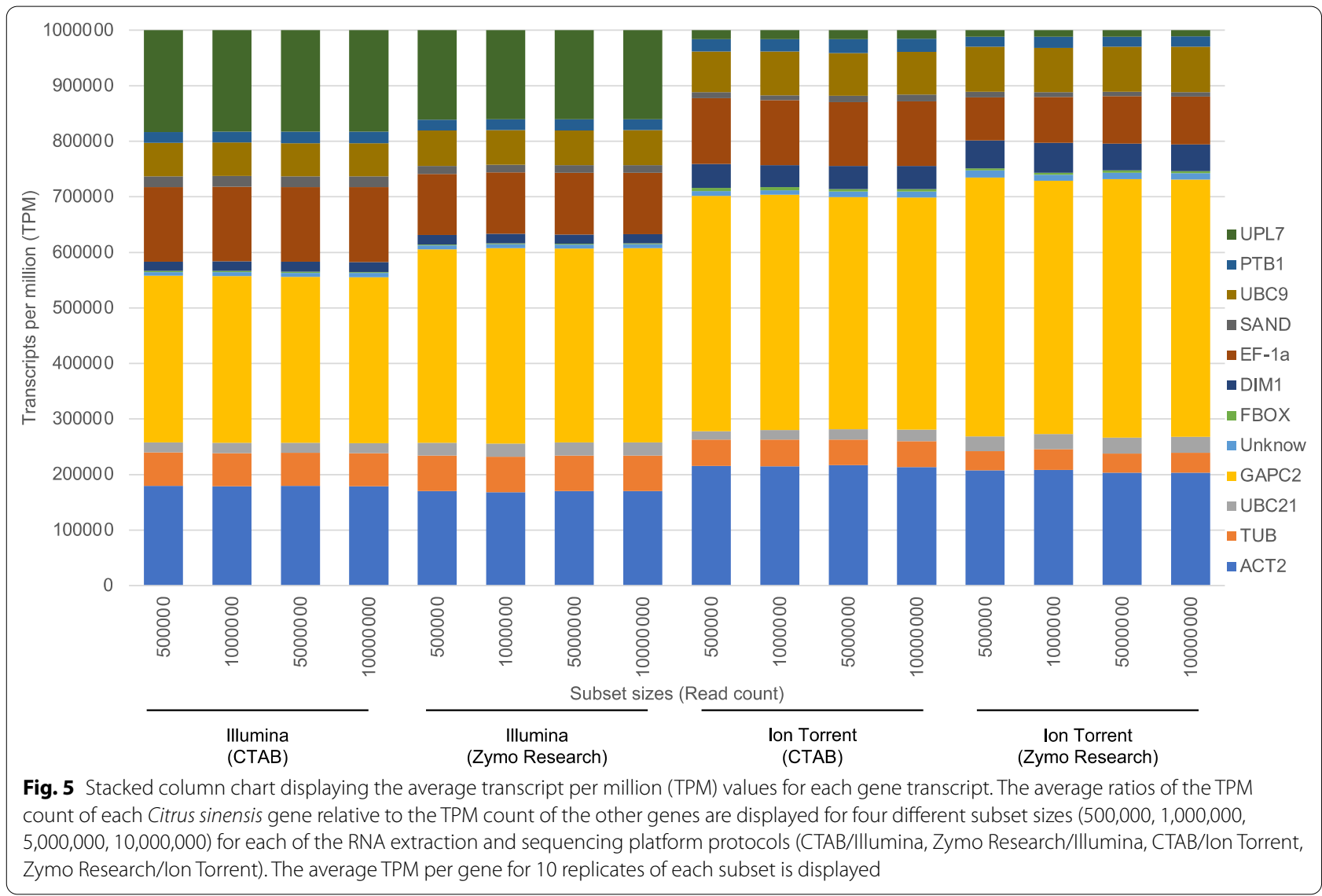

file 4). The relative ratio between the 12 different genes' TPM counts remained consistent across the different subset sizes (Fig. 5). The same variation in the TPM count of UPL7 and GAPC2 between the two sequencing platforms was observed across different subset sizes.

\section{Pathogen read mapping}

Reads were mapped to reference genomes of the viruses and viroids identified using the expected virome including CTV genotype RB, CiVA RNA 1 and 2, CTLV, HSVd, CDVd and CEVd (Table 1). Concurrently, reads were also mapped to the nontarget CTV genotype T68 and the Cachexia causing variant of HSVd [57, 58]. The principal component analysis of the pathogen TPM count data showed clear clusters of data points indicating the variation between the different extraction/platform protocols (Fig. 3b).

The expected virome was detected using read mapping with all four extraction/platform protocols. The TPM count for each pathogen for each extraction/platform protocol is illustrated in Fig. 6. The viroid TPM component of the CTAB extracted samples were much smaller compared to the Zymo Research kit extracted RNA samples, independent of sequencing platform. More variation in pathogen TPM count between the technical replicates of each biological sample was also observed in the Zymo Research data (Fig. 6).

All protocols obtained more than 99\% genome coverage (percentage of bases covered on the reference genome) for CTV genotype RB (KU883265), CTLV (MH108976.1), HSVd (KY110716.1), CEVd (KY110721.1), and CiVA RNA1 (MT720885) and CiVA RNA2 (MT720886) (Fig. 7). The only exception was CDVd (KY110718.1) that had a genome coverage of $100 \%$ with the Ion Torrent protocol irrespective of extraction method. With the Illumina protocol an average of $98.4 \%$ and $99 \%$ coverage was obtain with CTAB extractions and the Zymo Research kit, respectively (Fig. 7). Read mapping to the nontarget CTV genotype T68 showed an average genome coverage of only $78 \%, 73 \%, 83 \%$ and $78 \%$ for the CTAB/Illumina, Zymo Research/Illumina, CTAB/ Ion Torrent and Zymo Research/Ion Torrent protocols, respectively. Read mapping to the nontarget Cachexia causing variant of HSVd showed only $38 \%, 61 \%, 36 \%$ and $53 \%$ average genome coverage for the four extraction/ platform protocols (Fig. 7).

The Ornithogalum nontarget positive control data was also mapped to all the citrus pathogens to evaluate 

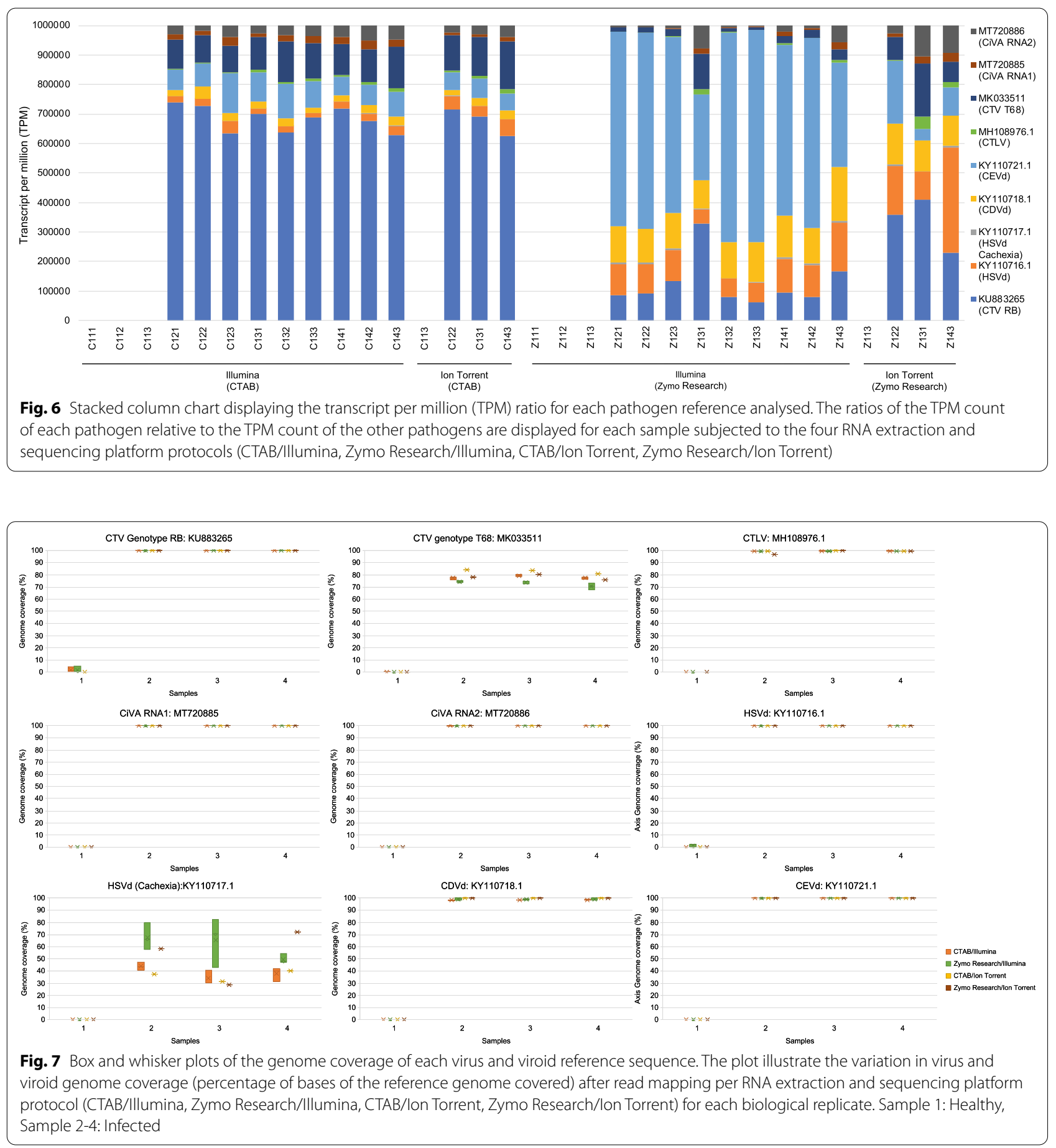

the level of cross-contamination between samples. Only seven, two and one reads mapped to CTV (KU883265), CTV (MK033511) and CiVA (MT720885), respectively. The citrus Illumina data sets were also mapped to OrMV (KY769694.1) and on average 197 reads (minimum:32, maximum:788) mapped from the CTAB/Illumina data and 60 reads (minimum:0, maximum:182) of the Zymo
Research/Illumina data mapped. The negative control data was also mapped to all the pathogens and the highest read count obtained was 22 reads (Illumina) and one read (Ion Torrent) for CTV (KU883265). 


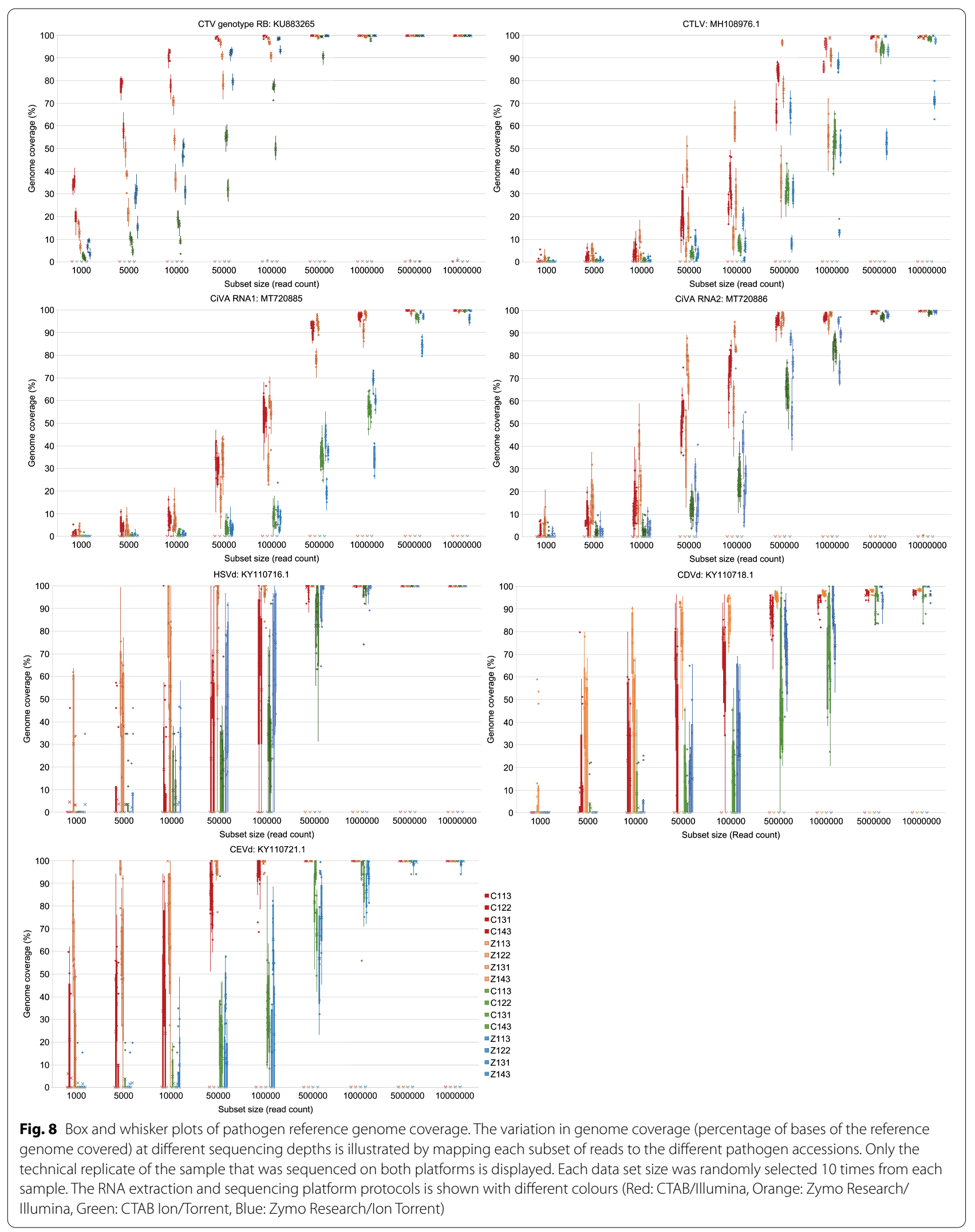


(See figure on next page.)

Fig. 9 Box and whisker plots of reference gene coverage. The variation in genome coverage (percentage of bases of the reference genome covered) at different sequencing depths is illustrated by mapping each subset of reads to the different gene accessions. Only the technical replicate of the sample that was sequenced on both platforms is displayed. Each data set size was randomly selected 10 times from each sample. The RNA extraction and sequencing platform protocol is shown with different colours (Red: CTAB/lllumina, Orange: Zymo Research/lllumina, Green: CTAB/ Ion Torrent, Blue: Zymo Research/lon Torrent)

\section{Sequencing depth}

Subsampling the original data into nine different sized data subsets showed the influence of sequencing depth on the potential genome/transcript coverage that can be obtained. Overall, the Illumina data reached a higher genome coverage with less data for both the pathogen and gene reference sequences (Figs. 8 and 9).

With the 10,000,000 reads subset an average target pathogen genome coverage of $99.5 \%, 99.6 \%, 99.2 \%$ and $98.0 \%$ was obtained for the CTAB/Illumina, Zymo Research/Illumina, CTAB Ion/Torrent and Zymo Research/Ion Torrent protocols, respectively (Additional file 5).

Since a previous CTV study showed that it is possible to obtain up to $90 \%$ genome coverage for nontarget genotypes [46], a 90\% genome coverage threshold was selected to evaluate for each of the virus and viroid accessions. Even though it was possible to obtain more than 90\% genome coverage for CTV with the 50,000 reads subset (all subset replicates from each technical replicate) using the $\mathrm{CTAB} /$ Illumina protocol, the one million reads subset was required to obtain at least $90 \%$ coverage for CTV with all four extraction/platform protocols (Additional file 5, Fig. 8).

To obtain a more than $90 \%$ genome coverage for all target pathogens the five million reads subset was needed with the CTAB/Illumina protocol. However for the other three extraction/platform protocols at least the ten million reads subset was required for more than $90 \%$ genome coverage consistently over all subset and technical replicates (Additional file 5).

The five million reads subset of the CTAB/Illumina protocol was able to consistently obtain a more than $90 \%$ genome coverage for all viruses and viroids, separately. However, with the Zymo Research/Illumina protocol at least $90 \%$ genome coverage of the viruses was obtained with the ten million reads subset and for the viroids with the one million reads subset (Additional file 5). The $\mathrm{CTAB} /$ Ion Torrent protocol required the ten million and five million reads subset for at least $90 \%$ genome coverage of the viruses and viroids, respectively while the Zymo Research/Ion Torrent protocol required the ten million reads subset for both viruses and viroids (Additional file 5).

The Zymo Research/Ion Torrent protocol data was unable to obtain a $90 \%$ or higher CTLV genome coverage consistently for all replicates (Additional file 5). The most variation in genome coverage at the lower data set sizes was obtained for the viroid sequences (Fig. 8).

The average reference gene accession coverage with the $10,000,000$ reads subset size was $91.3 \%, 89.7 \%, 71.3 \%$ and $73.4 \%$ for the CTAB/Illumina, Zymo Research/Illumina, CTAB/Ion Torrent and Zymo Research/Ion Torrent protocols, respectively (Additional file 5).

\section{Discussion}

In this study an experimentally constructed citrus virome was characterised using HTS to evaluate the influence of sampling, RNA extraction method, sequencing platform and data analysis pipeline. Four sweet orange (cv. 'Madam Vinous') trees were prepared, one negative control and three graft inoculated with CTV, CTLV, CiVA, HSVd, CDVd and CEVd. Each plant was sampled three times at the same timepoint, and RNA extracted using two different methods. Two sequencing platforms were selected to generate data from three samples from four plants (Illumina) and one sample from four plants (Ion Torrent). All data sets were subjected to a reference independent de novo assembly approach and a dependent read mapping strategy to determine the virome profile of each plant sample.

HTS can be utilised for both detection and discovery and the acceptable level of variation in specificity, sensitivity and repeatability that can be tolerated will depend on the application. In the present study, the detection of virus and viroid species were evaluated for application as a routine diagnostic assay. Identifying the exact virus or viroid variant, for example, was therefore not required for pathogen detection.

HTS is intrinsically specific and is therefore only limited by the accuracy of the base calls, the depth of the data and the completeness of the reference databases [15]. A public reference database can be incomplete due to novel viruses or new variants of viruses that are yet to be discovered. Local databases require continuous upkeep to be complete, even if it is only for virus species or variant additions. Nonetheless, novel pathogens or different variants of known pathogens not contained in a local database can, in some cases, still be detected by de novo assembly followed by homology searches and read mapping, just with lower confidence levels and less robustness. The limitations of such databases 

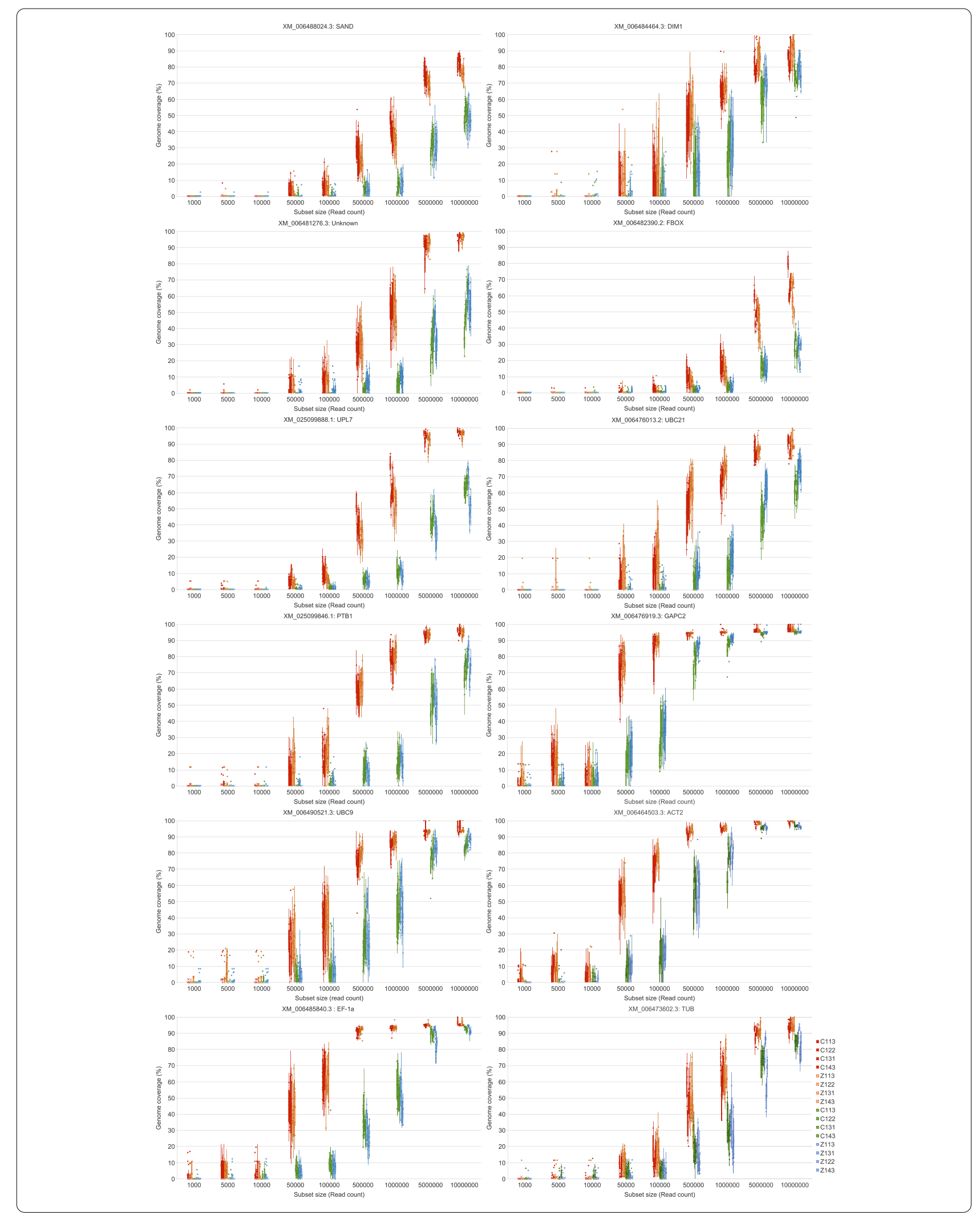
should be considered throughout the data analysis and interpretation.

The composition of the starting nucleic acids additionally impacts detection specificity. The virome profiles of the Zymo Research kit extracted samples were less consistent across samples and replicates than the profiles of the CTAB extracted samples (Fig. 6). This variation can be due to several fundamental differences in the RNA extraction protocols. The input plant material amount for the CTAB extraction method is one gram compared to the $200 \mathrm{mg}$ input for the Zymo Research kit. It is more difficult to obtain a representative sample using a lower input extraction method. This can potentially lead to the generation of false negative results if the virome includes pathogens that are unevenly distributed in the plant as was observed for plum pox virus (PPV) [59] and certain grapevine viruses [60].

The lower weight input restriction of the Zymo Research RNA extraction kit resulted in greater variation in the virome profiles between the technical replicates of each biological sample (Fig. 6), probably due to sectorial differences in concentrations of the target pathogens in the plants. The CTAB method yielded more consistent virome profiles between samples, likely due to the ability to process a more homogeneous sample, however this method appears to have a slight bias against viroid sequences. Collectively, this virome analysis indicates that a low weight input extraction method has risk implications for use in a routine HTS detection assay.

Reproducibility is required at each step of the HTS assay, from nucleic acid extraction to data interpretation. Previous studies highlighted the link between appropriate depth of coverage and the repeatability of the assay [37, 40], but no systematic studies on repeatability and reproducibility have been published. In this study an attempt at reproducibility was made by including both biological and technical replicates for the Illumina sequencing protocol.

The two different extraction methods yielded total RNA with different rRNA profiles. No significant difference between the RIN values for the two groups was observed, however the rRNA ratio of the Zymo Research kit extracted RNA was significantly lower than for the CTAB RNA due to a higher concentration of $5 \mathrm{~S}$ rRNA yielded by the Zymo Research kit. This indicates a potential difference in the RNA species extracted with each method and it is possible that the CTAB extraction selected against viroid sequences due to the Lithium Chloride $(\mathrm{LiCl})$ precipitation step. The SPAdes de novo assembly of the Illumina data did not produce viroid scaffolds for one technical replicate of two different CTAB extracted samples, compared to all the expected viroid scaffolds assembled in the Zymo Research kit replicates
(Additional file 2). The SPAdes assemblies of the Zymo Research data also generated more viroid scaffolds compared to the CTAB data (Fig. 2). The read mapping strategy also displayed the difference in viroid RNA concentration between the two extraction methods where the ratios of pathogen concentration was vastly different between the extraction methods, independent of the sequencing platform (Fig. 6). More viroid RNA reads were obtained using the Zymo Research kit. Due to the potential lower representation of viroid RNA obtained with certain extraction methods and the small genome size of viroids, it is possible that a viroid infection may be missed with only a de novo assembly approach. Although, the RNA extraction method influenced the performance of the detection assay in the present study, it did not alter the final combined de novo and read mapping results (Additional file 2, Additional file 5) and all pathogens were consistently detected.

The selection in de novo assembler can influence the result as seen in the contigs assembled with CGW compared to the SPAdes scaffolds (Additional file 2). The SPAdes assembly with the Illumina data performed better in confirming the expected virome profile compared to the assemblies with the Ion Torrent data. Both assemblers were able to assemble more and longer contigs/scaffolds with the Illumina data. Even though 1.2 times more Ion Torrent data than Illumina data was obtained from the service providers, the $196 \mathrm{nt}$ read distance between the paired-end reads of the Illumina data may contribute to better contig assemblies compared to the single-end Ion Torrent reads with an average length of $137 \mathrm{nt}$.

The principal component analyses using the TPM counts of the pathogen and gene accession read mappings showed a clear separation between the different extraction/platform protocols (Fig. 3). However, for the gene accessions, the most variation was between sequencing platforms and for the pathogens the variation was between RNA extraction methods (Fig. 3). This is partially explained by the viroid component of the pathogen profile that was greater in the Zymo Research data sets. The variation between technical replicates was however minimal and the variation observed was rather as a result of extraction method or sequencing platform.

The investigation into the expression profile of reference genes allowed the comparison between samples across different extraction/platform protocols to potentially answer questions relating to the suitability of the sequencing depth to address pathogen detection. The expression pattern of these genes is hypothesized to be stable and even if the gene expression is modulated in response to biotic stress, the variation between samples should be reflected in each of the different extraction/ platform protocols selected. By identifying low and high 
expressing genes, gene expression profiles can be used as internal controls for RNA extraction efficiency, library construction and also to determine the number of reads required for accurate detection. Using the host reference gene mapping ratios, outlier samples can be identified as seen for sample C122 (Illumina) (Fig. 4). The expression pattern of the 12 genes selected in this study showed a consistent pattern across extraction methods but differed for each of the sequencing platforms (Fig. 4). No significant variation in expression patterns were observed between healthy and infected plants. The different pattern per sequencing platform was also consistent, independent of data set size (Fig. 5). Therefore, based on the data generated in this study, UPL7 and GAPC2 might not be consistent internal controls for cross platform comparisons, however, when selecting a single platform, these genes can be used. The reference genes can also be used to normalise the virus or viroid TPM count to allow for direct virus and viroid concentration comparisons between samples. Only five of the gene accessions had a consistent gene coverage of more than $90 \%$ for all technical and subset replicates (Additional file 5).

The expected virome was confirmed with RT-PCR and included five CTV genotypes (RB, VT, T3, T30 and S1), CTLV, CiVA and three viroids (HSVd, CDVd and CEVd). The influence of read mapping to a distant variant of the target virus/viroid was assessed by including nontarget reference sequences of CTV (genotype T68) and the Cachexia variant of HSVd. An average genome coverage for CTV genotype T68 of $73-83 \%$ was obtained for the four different extraction/platform protocols. Compared to the genome coverage of the expected CTV genotype $\mathrm{RB}$ of $>99 \%$, the T68 read mappings are distinguishable as false positive mappings. A previous study showed that it is possible to obtain up to $90 \%$ coverage for nontarget genotypes in mixed genotype infections and that read mapping across more than $95 \%$ of the genome is indicative of the presence of a particular genotype [46]. Due to the extent of variation between CTV genotypes (2-9\%) [46], the selection of reference sequences will influence the coverage percentage. Therefore, if a reference for a genotype not present in the data is used for read mapping, a lower percentage would still be indicative of the presence of CTV, but just that a different CTV genotype than the reference would be expected. This would be true for most viruses and by including representative sequences of the different genotypes in the read mapping strategy, false negative diagnostic calls can be prevented. In the case of HSVd it is important to be able to differentiate between disease causing and latent variants since they are biologically distinct in citrus. The nontarget Cachexia variant of the HSVd genome was only $36 \%$ $61 \%$ covered for the four different extraction/platform protocols, clearly indicating that this variant was not present in the samples.

The sensitivity of any detection assay is directly linked to the proportion of viral RNAs among the host cellular RNAs. Therefore, sequencing depth plays an important role in the reliability of the HTS assay. The main conclusion from the subset experiment in this study was that less Illumina data was needed to obtain complete or near complete genomes of the expected pathogens and the Ion Torrent data can perform on par with Illumina if more reads are used for the read mapping. The number of bases in each subset size for the Ion Torrent data was 1.3-1.4 times more compared to the Illumina subsets as a consequence of the longer read length. However, the average distance of 196 bases between the Illumina read pairs may have increased the efficacy of the Illumina read mapping.

The finding of a previous study [37] that showed that sequencing one million reads will provide sufficient genome coverage for closterovirus detection, was confirmed (Fig. 8, Additional file 5). It was also shown that a higher number of reads is needed for other pathogens depending on the extraction/platform protocol. Viroid detection was shown to be variable and even though it was possible to obtain a complete genome with lower read numbers, the detection is only consistent with more sequencing depth.

No citrus pathogen sequences were de novo assembled from the Ornithogalum nontarget positive control or C. sinensis negative control data that was included in the Illumina and Ion Torrent sequencing runs and no pathogens associated with Ornithogalum were assembled from the citrus RNA data. The Ornithogalum data set were mapped to the citrus pathogens and negligible read counts were obtained. A maximum of 788 citrus RNA reads from the different samples mapped to ornithogalum mosaic virus however the genome coverage never reached more than $1.5 \%$. This indicated no significant cross-contamination between samples.

The reproducibility of this study was not measured specifically, as a true test of reproducibility would require an interrogation of the extent to which consistent results could be obtained by repetition of the whole experiment at different timepoints. An attempt at reproducibility was made to include both biological and technical replicates for the Illumina sequencing protocol. The technical replicates were however not sequenced on the Ion Torrent platform due to a cost implication. The Ion torrent data cost 43\% more for the same amount of Illumina data.

In this biological context, reproducibility will not be completely achievable as variables such as plant age, growth stage and virus concentration linked to infection duration might influence the outcome. 
A comparison of single-end data from the Illumina platform and single-end data from the Ion Torrent platform was not evaluated to keep the generation of data as close to a real-case scenario as possible. The two service providers, Macrogen and CAF, provide by default, paired-end Illumina and single-end Ion Torrent data, respectively.

\section{Conclusions}

This study is a detailed measurement of technical variation in HTS data associated with the detection of viruses and viroids in citrus. The study evaluated the efficiency of using HTS to detect two single stranded RNA viruses from different families, a negative-sense single-stranded RNA virus and three viroid species. The study evaluated the influence of RNA extraction protocol, sequencing platform and data analysis pipelines on the sensitivity, specificity and repeatability of HTS as a detection tool. Each of these parameters introduce a different bias that creates variation in the data output. Even though the different extraction methods, sequencing platform and data analysis tools resulted in variation in the present study, the end result being the virome profile of each sample could be confirmed independent of the HTS approach. The study highlights the need to be aware of the level of variation associated with each approach in strategy, from sample collection to data interpretation and how these variables may impact on the initial objective of the HTS assay. This awareness is critical to enable informed adjustments to correctly interpret the data for a reliable results. The primary recommendation that follows from this study is that, irrespective of extraction method or sequencing platform, a combination of de novo assembly and read mapping be used for a routine detection assay.

Since the goal of this study was to evaluate HTS as a detection tool in quarantine or certification schemes, and not for discovery purposes, a list of known pathogens should be available in these settings for read mapping. The aim of a de novo assembly in the certification scheme context will be to identify unsuspected pathogens. ${ }^{1}$ The absence of virus/viroid related de novo assembled contigs does not automatically indicate a negative status for the respective pathogen and read mapping is required as a validation step to confirm absence. This is especially necessary for low concentration viruses and viroids. Read mapping against multiple reference genes as internal

\footnotetext{
${ }^{1}$ The primary application described here is for routine virus detection and hence the de novo assembly step is not critical for this application. However, it would be short-sighted not to include this step that provides an extra layer of security. Unsuspected or novel viruses detected in these assays will require additional validation, contrary to the detection of known pathogens for which this assay was validated.
}

controls is also recommended to establish gene ratios for a specific assay. This allows for the evaluation of sequencing depth to accurately determine the absence of lowlevel infections. The inclusion of a nontarget positive and a negative control can assist significantly to evaluate cross contamination between samples. The final conclusion is that sequencing depth matters and that with enough data the variation observed between extraction methods and sequencing platforms are diminished and equivalent results can be obtained.

The application of HTS for the detection of plant viruses is commonly described as being unbiased, however this is only true within a specific context, in that it does not require any prior knowledge of the pathogens. There are however, slight biases and variations at every step of an HTS assay, as demonstrated, but which can easily be corrected for when quantified. This study provides strong evidence that the application of HTS for routine pathogen detection is attainable if the detection pipeline is critically validated.

\begin{abstract}
Abbreviations
HTS: High-throughput sequencing; CTV: Citrus tristeza virus; CTLV: Citrus tatter leaf virus; HSVd: Hop stunt viroid; CDVd: Citrus dwarfing viroid; CEVd: Citrus exocortis viroid; CiVA: Citrus virus A; CLaf: Candidatus Liberibacter africanus; CRI: Citrus Research International; CDNA: Complementary DNA; dNTPs: Deoxyribonucleotide triphosphate; OrMV: Ornithogalum mosaic virus; RIN: RNA integrity number; bp: Base pair; nt: Nucleotide; CGW: CLC genomics Workbench; BWA: Burrows-Wheeler Alignment Tool; NCBI: National Center for Biotechnology Information; TPM: Transcripts per million; RPK: Read count per kilobase of sequence; CRAN: Comprehensive R Archive Network; rRNA: Ribosomal RNA; CTAB: Cetyltrimethylammonium bromide; RNA: Ribonucleic acid; OV3: Ornithogalum virus 3; GAPC2: Glyceraldehyde-3-phosphate dehydrogenase C2; EF-1a: Elongation factor 1-alpha; ACT2: Actin-2; FBOX: F-box family protein; UPL7: Ubiquitin-protein ligase 7; cv:: Cultivar; sRNA: Small RNA; PPV: Plum pox virus; LiCl: Lithium chloride.
\end{abstract}

\section{Supplementary Information}

The online version contains supplementary material available at https://doi. org/10.1186/s12985-021-01523-1.

Additional file 1Species and strain-specific primer sequences used in a two-step RT-PCR to amplify citrus viruses and viroids.

Additional file 2Descriptive statistics of high-throughput sequencing data generated and the identification of contigs/scaffolds per de novo assembly.

Additional file 3Descriptive statistics of the TPM values for the different gene accessions used as internal control references.

Additional file 4 Statistical tests performed using the Kruskal-Wallis rank sum test between the data distributions of the different extraction methods and sequencing platform data sets based on transcripts per million (TPM) counts per gene analysed. Significant differences are indicated in bold if the $p$ value $<0.05$.

Additional file $\mathbf{5}$ The subset sizes for which the respective accession obtained a $90 \%$ and $95 \%$ genome coverage for all sample and subset replicates with read mapping per RNA extraction method and sequencing platform protocol. 


\section{Acknowledgements}

Computations were performed using the Stellenbosch University's HPC2: http://www.sun.ac.za/hpc. The authors also thank Dr. Adrian Fox for the useful discussions and critical reading of the manuscript.

\section{Authors' contributions}

HJM designed the study; JHJB established and maintained all the plant material; GC, CS and RdB performed the RT-PCRs; RB conducted the bioinformatic analyses; RB, HJM interpreted the results and drafted the manuscript. All authors read and approved the final manuscript.

\section{Funding}

The authors thank Citrus Research International (CRI) and Research for Citrus Exports Fund of the Department of Science and Innovation (DSI), South African Government for funding CRI project 1241. Opinions expressed and conclusions arrived at, are those of the authors and are not necessarily to be attributed to CRI and DSI.

\section{Availability of data and materials}

The datasets used and/or analysed during the current study are available from the corresponding author on reasonable request.

\section{Declaration}

Ethics approval and consent to participate

Not applicable.

\section{Consent for publication}

Not applicable.

\section{Competing interests}

The authors declare that they have no competing interests.

\section{Author details}

1 Department of Genetics, Stellenbosch University, Private Bag X1, Matieland 7602, South Africa. ${ }^{2}$ Citrus Research International, P.O. Box 28, Nelspruit 1200, South Africa. ${ }^{3}$ Department of Plant Pathology, Stellenbosch University, Private Bag X1, Matieland 7602, South Africa. ${ }^{4}$ Citrus Research International, P.O. Box 2201, Matieland 7602, South Africa.

Received: 17 December 2020 Accepted: 2 March 2021

Published online: 22 March 2021

\section{References}

1. Al Rwahnih M, Daubert S, Golino D, Rowhani A. Deep sequencing analysis of RNAs from a grapevine showing Syrah decline symptoms reveals a multiple virus infection that includes a novel virus. Virology. 2009:387:395-401.

2. Kreuze JF, Perez A, Untiveros M, Quispe D, Fuentes S, Barker I, et al. Complete viral genome sequence and discovery of novel viruses by deep sequencing of small RNAs: a generic method for diagnosis, discovery and sequencing of viruses. Virology. 2009;388:1-7.

3. Al Rwahnih M, Sudarshana MR, Uyemoto JK, Rowhani A. Complete genome sequence of a novel vitivirus isolated from grapevine. J Virol. 2012:86:9545-9545

4. Espach Y, Maree HJ, Burger JT. Complete genome of a novel endornavirus assembled from next-generation sequence data. J Virol. 2012:86:13142-13142

5. Villamor DEV, Mekuria TA, Pillai SS, Eastwell KC. High-Throughput sequencing identifies novel viruses in nectarine: insights to the etiology of stem-pitting disease. Phytopathology. 2016;106:519-27.

6. Navarro B, Minutolo M, Stradis AD, Palmisano F, Alioto D, Serio FD. The first phlebo-like virus infecting plants: a case study on the adaptation of negative-stranded RNA viruses to new hosts. Mol Plant Pathol. 2017; 19:1075-89.

7. Navarro B, Zicca S, Minutolo M, Saponari M, Alioto D, Di Serio F. A Negative-Stranded RNA Virus Infecting Citrus Trees: The Second Member of a New Genus Within the Order Bunyavirales. Frontiers in Microbiology.
2018 [cited 2018 Oct 24];9. Available from: https://doi.org/10.3389/fmicb. 2018.02340/full

8. Rott ME, Kesanakurti P, Berwarth C, Rast H, Boyes I, Phelan J, et al. Discovery of negative-sense RNA viruses in trees infected with apple rubbery wood disease by next-generation sequencing. Plant Dis. 2018;102:1254-63.

9. Diaz-Lara A, Navarro B, Di Serio F, Stevens K, Hwang MS, Kohl J, et al. Two novel negative-sense RNA viruses infecting grapevine are members of a newly proposed genus within the family phenuiviridae. Viruses. 2019;11:685.

10. Chiapello M, Rodríguez-Romero J, Nerva L, Forgia M, Chitarra W, Ayllón MA, et al. Putative new plant viruses associated with Plasmopara viticola -infected grapevine samples. Ann Appl Biol. 2020;176:180-91.

11. Pooggin MM. Small RNA-omics for plant virus identification, virome reconstruction, and antiviral defense characterization. Front Microbiol. 2018;9:2779.

12. Barba M, Czosnek $H$, Hadidi A. Historical perspective, development and applications of next-generation sequencing in plant virology. Viruses. 2014;6:106-36

13. Maliogka V, Minafra A, Saldarelli P, Ruiz-García A, Glasa M, Katis N, et al. Recent advances on detection and characterization of fruit tree viruses using high-throughput sequencing technologies. Viruses. 2018;10:436.

14. Olmos A, Boonham N, Candresse T, Gentit P, Giovani B, Kutnjak D, et al. High-throughput sequencing technologies for plant pest diagnosis: challenges and opportunities. EPPO Bull. 2018;48:219-24.

15. Maree HJ, Fox A, Al Rwahnih M, Boonham N, Candresse T. Application of HTS for Routine Plant Virus Diagnostics: State of the Art and Challenges. Front Plant Sci. 2018 [cited 2019 Nov 12];9. Available from: https://doi. org/10.3389/fpls.2018.01082/full

16. Villamor DEV, Ho T, Al Rwahnih M, Martin RR, Tzanetakis IE. High throughput sequencing for plant virus detection and discovery. Phytopathology. 2019;109:716-25

17. Maclot F, Candresse T, Filloux D, Malmstrom CM, Roumagnac $P$, van der Vlugt $R$, et al. Illuminating an ecological blackbox: using high throughput sequencing to characterize the plant virome across scales. Front Microbiol. 2020;11:578064

18. Roossinck MJ. Metagenomics of plant and fungal viruses reveals an abundance of persistent lifestyles. Front Microbiol. 2015 [cited 2018 May 22];5. https://doi.org/10.3389/fmicb.2014.00767/abstract

19. Barrero RA, Napier KR, Cunnington J, Liefting L, Keenan S, Frampton $R A$, et al. An internet-based bioinformatics toolkit for plant biosecurity diagnosis and surveillance of viruses and viroids. BMC Bioinf. 2017;18:26.

20. Rott M, Xiang Y, Boyes I, Belton M, Saeed H, Kesanakurti P, et al. Application of next generation sequencing for diagnostic testing of tree fruit viruses and viroids. Plant Dis. 2017;101:1489-99.

21. Ho T, Tzanetakis IE. Development of a virus detection and discovery pipeline using next generation sequencing. Virology. 2014;471-473:54-60.

22. Zhao G, Krishnamurthy S, Cai Z, Popov VL, Travassos da Rosa AP, Guzman $\mathrm{H}$, et al. Identification of Novel Viruses Using VirusHunter - an Automated Data Analysis Pipeline. Dutilh BE, editor. PLOS ONE. 2013;8:e78470.

23. Jooste TL, Visser M, Cook G, Burger JT, Maree HJ. In Silico probebased detection of citrus viruses in NGS data. Phytopathology ${ }^{\circledR}$ 2017;107:988-93.

24. Seguin J, Otten P, Baerlocher L, Farinelli L, Pooggin MM. MISIS: a bioinformatics tool to view and analyze maps of small RNAs derived from viruses and genomic loci generating multiple small RNAs. J Virol Methods. 2014:195:120-2.

25. Stobbe AH, Schneider WL, Hoyt PR, Melcher U. Screening metagenomic data for viruses using the E-probe diagnostic nucleic acid assay. Phytopathology ${ }^{\circledR}$. 2014;104:1125-9.

26. de Andrade RR, Vaslin MF. SearchSmallRNA: a graphical interface tool for the assemblage of viral genomes using small RNA libraries data. Virol J. 2014;11:45

27. Charlebois RL, Sathiamoorthy S, Logvinoff C, Gisonni-Lex L, Mallet L, Ng SHS. Sensitivity and breadth of detection of high-throughput sequencing for adventitious virus detection. npj Vaccines. 2020;5:61.

28. Li Y, Wang H, Nie K, Zhang C, Zhang Y, Wang J, et al. VIP: an integrated pipeline for metagenomics of virus identification and discovery. Sci Rep. 2016;6:23774. 
29. Watson M, Schnettler E, Kohl A. viRome: an R package for the visualization and analysis of viral small RNA sequence datasets. Bioinformatics. 2013;29:1902-3

30. Zheng Y, Gao S, Padmanabhan C, Li R, Galvez M, Gutierrez D, et al. VirusDetect: An automated pipeline for efficient virus discovery using deep sequencing of small RNAs. Virology. 2017;500:130-8.

31. Wang Q, Jia P, Zhao Z. VirusFinder: software for efficient and accurate detection of viruses and their integration sites in host genomes through next generation sequencing data. Zhu D, editor. PLoS ONE. 2013;8:e64465.

32. Zhao G, Wu G, Lim ES, Droit L, Krishnamurthy S, Barouch DH, et al. VirusSeeker, a computational pipeline for virus discovery and virome composition analysis. Virology. 2017:503:21-30.

33. Chen Y, Yao H, Thompson EJ, Tannir NM, Weinstein JN, Su X. VirusSeq: software to identify viruses and their integration sites using next-generation sequencing of human cancer tissue. Bioinformatics. 2013;29:266-7.

34. Yamashita A, Sekizuka T, Kuroda M. VirusTAP: Viral genome-targeted assembly pipeline. Front Microbiol. 2016 [cited 2020 Oct 22];7. https://doi. org/10.3389/fmicb.2016.00032/abstract

35. Antoniewski C. Visitor, an informatic pipeline for analysis of viral siRNA sequencing datasets. In: van Rij RP (eds). Antiviral RNAi: concepts, methods, and applications [Internet]. Totowa, NJ: Humana Press; 2011. p. 123-42. https://doi.org/10.1007/978-1-61779-037-9_7

36. Visser M, Burger JT, Maree HJ. Targeted virus detection in next-generation sequencing data using an automated e-probe based approach. Virology. 2016:495:122-8.

37. Visser M, Bester R, Burger JT, Maree HJ. Next-generation sequencing for virus detection: covering all the bases. Virol J. 2016;13:85.

38. Visser M, Maree HJ, Rees DJ, Burger JT. High-throughput sequencing reveals small RNAs involved in ASGV infection. BMC Genom. 2014;15:568.

39. Massart S, Chiumenti M, De Jonghe K, Glover R, Haegeman A, Koloniuk I, et al. Virus detection by high-throughput sequencing of small rnas: largescale performance testing of sequence analysis strategies. Phytopathology. 2019;109:488-97.

40. Pecman A, Kutnjak D, Gutiérrez-Aguirre I, Adams I, Fox A, Boonham N, et al. Next generation sequencing for detection and discovery of plant viruses and viroids: comparison of two approaches. Front Microbiol. 2017 [cited 2018 May 22];8. https://doi.org/10.3389/fmicb.2017.01998/full

41. Edmonds J. Citrus Growers' Association (CGA) Key Industry Statistics 2020. Citrus Growers' Association of Southern Africa; 2020 [cited 2020 Dec 8]. Available from: https://www.citrusresourcewarehouse.org.za/home/ document-home/information/cga-key-industry-statistics/6550-cga-keyindustry-statistics-2020/file

42. Moreno P, Ambrós S, Albiach-Martí MR, Guerri J, Peña L. Citrus tristeza virus: a pathogen that changed the course of the citrus industry. Mol Plant Pathol. 2008;9:251-68.

43. Bar-Joseph M, Marcus R, Lee RF. The continuous challenge of citrus tristeza virus control. Annu Rev Phytopathol Annu Rev. 1989;27:291-316.

44. Bester R, Karaan M, Cook G, Maree HJ. First report of citrus virus A in citrus in South Africa. J Citrus Pathol. 2021;8. https://escholarship.org/uc/item/ 5 gr6p8zh

45. Cook G, van Vuuren SP, Breytenbach JHJ, Burger JT, Maree HJ. Expanded strain-specific RT-PCR assay for differential detection of currently known Citrus Tristeza Virus strains: a useful screening tool. J Phytopathol. 2016;164:847-51.

46. Ruiz-García AB, Bester R, Olmos A, Maree HJ. Bioinformatic tools and genome analysis of Citrus tristeza virus. In: Catara AF, Bar-Joseph M, Licciardello G (eds) Citrus Tristeza Virus: Methods and Protocols. New York, NY: Springer New York; 2019. p. 163-78. https://doi.org/10.1007/978-14939-9558-5_12

47. Bolger AM, Lohse M, Usadel B. Trimmomatic: a flexible trimmer for Illumina sequence data. Bioinformatics. 2014;30:2114-20.

48. Nurk S, Bankevich A, Antipov D, Gurevich A, Korobeynikov A, Lapidus A, et al. Assembling genomes and mini-metagenomes from highly chimeric reads. In: Deng M, Jiang $R$, Sun F, Zhang X (eds) Research in computational molecular biology. Berlin, Heidelberg: Springer Berlin Heidelberg; 2013. p. 158-70.

49. Xu Q, Chen L-L, Ruan X, Chen D, Zhu A, Chen C, et al. The draft genome of sweet orange (Citrus sinensis). Nat Genet. 2013;45:59-66.

50. Li H, Durbin R. Fast and accurate short read alignment with BurrowsWheeler transform. Bioinformatics. 2009:25:1754-60.

51. Li H, Handsaker B, Wysoker A, Fennell T, Ruan J, Homer N, et al. The sequence alignment/map format and SAMtools. Bioinformatics. 2009;25:2078-9.

52. Bester R, Cook G, Maree HJ. citrus tristeza virus genotype detection using high-throughput sequencing. Viruses. 2021;13:17.

53. Mafra V, Kubo KS, Alves-Ferreira M, Ribeiro-Alves M, Stuart RM, Boava $L P$, et al. Reference genes for accurate transcript normalization in citrus genotypes under different experimental conditions. Zhang B (eds). PLoS ONE. 2012;7:e31263.

54. R Core Team. R: A language and environment for statistical computing [Internet]. Vienna, Austria.: R Foundation for Statistical Computing; Available from: https://www.R-project.org/

55. Hollander M, Wolfe DA. Nonparametric statistical methods. New York: John Wiley \& Sons; 1973.

56. Vu VQ. ggbiplot: A ggplot2 based biplot. R package version 0.55 [Internet]. 2011. Available from: http://github.com/vqv/ggbiplot

57. Serra P, Gago S, Duran-Vila N. A single nucleotide change in Hop stunt viroid modulates citrus cachexia symptoms. Virus Res. 2008;138:130-4.

58. Reanwarakorn K, Semancik JS. Correlation of hop stunt viroid variants to cachexia and xyloporosis diseases of citrus. Phytopathology ${ }^{\circledR}$. 1999;89:568-74.

59. Glasa M, Candresse T. Plum Pox Virus. In: Mahy BWJ, Van Regenmortel MHV, editors. Encyclopedia of Virology (Third Edition). Oxford: Academic Press; 2008. p. 238-42. http://www.sciencedirect.com/science/article/pii/ B9780123744104007366

60. Kominek P, Glasa M, Kominkova M. Analysis of multiple virus-infected grapevine plant reveals persistence but uneven virus distribution. av. 2009;53:281-5.

\section{Publisher's Note}

Springer Nature remains neutral with regard to jurisdictional claims in published maps and institutional affiliations.

Ready to submit your research? Choose BMC and benefit from

- fast, convenient online submission

- thorough peer review by experienced researchers in your field

- rapid publication on acceptance

- support for research data, including large and complex data types

- gold Open Access which fosters wider collaboration and increased citations

- maximum visibility for your research: over $100 \mathrm{M}$ website views per year

At BMC, research is always in progress.

Learn more biomedcentral.com/submissions 